\title{
A Case with Emanuel Syndrome Resulting from a Ma- ternal Balanced Translocation
}

\author{
Ja Hye Kim¹, Yoo-Mi Kim', Beom Hee Lee ${ }^{1,2}$, Ja-Hyung Kim³ ${ }^{3}$ Eul-Ju Seo ${ }^{2,4}$ and Han-Wook Yoo ${ }^{1,2^{*}}$ \\ ${ }^{1}$ Department of Pediatrics, Asan Medical Center, University of Ulsan College of Medicine, Seoul, Korea \\ ${ }^{2}$ Medical Genetics Center, Asan Medical Center, University of Ulsan College of Medicine, Seoul, Korea \\ ${ }^{3}$ Department of Pediatrics, Ulsan University Hospital, Ulsan, Korea \\ ${ }^{4}$ Department of Laboratory Medicine, Asan Medical Center, University of Ulsan College of Medicine, Seoul, Korea
}

Emanuel syndrome is a rare genomic syndrome which is characterized by multiple congenital anomalies and developmental disability. This syndrome is related to the presence of the supernumerary derivative chromosome originating from both chromosome 11 and 22. In most cases, one of the parents is a balanced carrier of a translocation. Our case results from 3:1 meiotic segregation of the maternal translocation carrier and is a rare case in Korea confirmed by genetic analysis.

Key Words: Emanuel syndrome, Supernumerary der(22) syndrome, Congenital abnormalities

\section{Introduction}

Emanuel syndrome is characterized by severe intellectual disability, failure to thrive, microcephaly, preauricular tag or sinus, ear anomalies, cleft or high-arched palate, micrognathia, kidney abnormalities, congenital heart defect, and genital abnormalities. ${ }^{1-4)}$ Affected children are usually identified in the newborn period as the offspring of balanced $(11 ; 22)$ translocation carriers. Carriers of this balanced translocation usually have no clinical symptoms and are often identified after the birth of offspring with an unbalanced form of the translocation, the supernumerary der(22)t(11;22)syndrome. This genomic syndrome was named Emanuel syndrome in 2004 [OMIM 609029]. This syndrome usually arises through 3:1 malsegregation during gametogenesis in a balanced t(11;22), and clustered breakpoints have been reported in numerous unrelated families. ${ }^{5,6)}$

Previously, a few cases have been reported as Emanuel syn- drome resulting from 3:1 meiotic segregation of the paternal translocation carrier in Korea (Table 1). ${ }^{7.8}$ In the current report, we present a female patient with supernumerary der(22) syndrome resulting from 3:1 meiotic segregation of the maternal translocation carrier. Our patient demonstrates the typical clinical manifestations as in the literatures, providing a better understanding of thissyndrome.

\section{Case Report}

The patient was born after 39 weeks of gestation weighing 2,780 gram, to a 35 -year-old mother in a local clinic. Her mother denied any history of illness, smoking, drug use, alcohol use during pregnancy. There is no family history of congenital anomalies, syndromes, or consanguinity. Her prenatal evaluation had been unremarkable. At birth, she was found to have a cleft palate, a

Received: 20 May 2012, Revised: 13 June 2012, Accepted: 21 June 2012, Published: 30 June 2012

${ }^{*}$ Corresponding author: Han-Wook Yoo

Department of Pediatrics, Asan Medical Center, University of Ulsan College of Medicine, 86, Asanbyeongwon-gil, Songpa-gu, Seoul 138-736, Korea Tel: +82-2-3010-3374, Fax: +82-2-473-3725, E-mail: hwyoo@amc.seoul.kr

(c) This is an open-access article distributed under the terms of the Creative Commons Attribution Non-Commercial License (http://creativecommons.org/licenses/by-nc/3.0/) which permits unrestricted non-commercial use, distribution, and reproduction in any medium, provided the original work is properly cited.

(c) Copyright 2012 by the Korean Society of Medical Genetics 
webbed neck, low-set ears, and micrognathia. Echocardiography revealed secundum atrial septal defect. She also has renal anomalies, a small left kidney and vesicoureteral reflux grade II on left side. On hearing assessment, she was suspicious of having sensorineural hearing loss. Karyotyping using her peripheral blood was done due to her multiple congenital anomalies, which revealed the chromosomal abnormality, 47,XX, $+\operatorname{der}(22) t(11 ; 22)$ (q23.3;q11.2) (Fig. 1). In addition, she was admitted to hospital repeatedly due to aspiration pneumonia or urinary tract infection. On the videofluoroscopic swallowing study, the severe velopharyngeal incoordination was noted.

At the age of 6 months, she was transferred to our hospital due to generalized tonic seizure. She could not control her head due to significant central hypotonia. Encephalogram showed diffusely suppressed electrical activities for her age, and diffuse brain atrophy with thinning of corpus callosum was noted on brain magnetic resonance imaging (MRI). To ascertain the origin and trait of this supernumerary marker chromosome, der(22)t(11;22) (q23.3;q11.2), karyotyping for her parents and sister were performed. The mother and her older sister were found to be a balanced carrier; $46, X X, t(11 ; 22)(q 23.3 ; q 11.2)$.

A

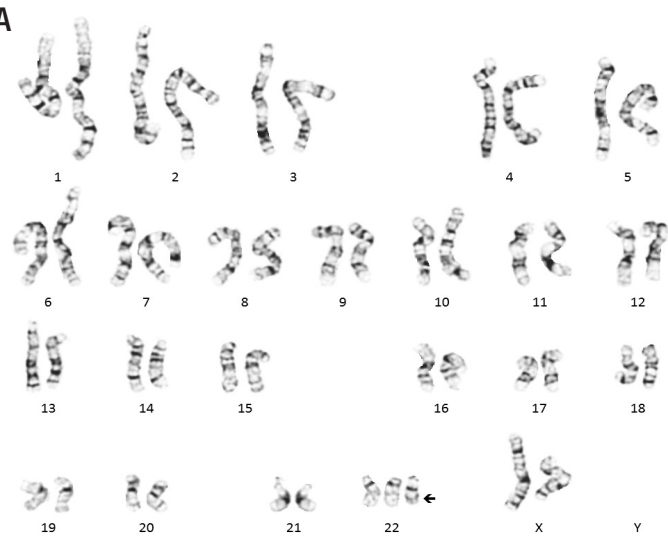

\section{Discussion}

Over 100 individuals with Emanuel syndrome have been reported. ${ }^{1-3)}$ Our patent is the 3rdKorean case, and has the typical features of Emanuel syndrome as described in the literature (Table 1). She has severe global developmental delay. Her longterm prognosis may be related to the associated congenital malformations and repeated infections, and she has to receive multidisciplinary management and intervention for cardiac defect, cleft palate, and seizure. Her older sister is a balanced t(11;22). Therefore, she has to receive prenatal diagnosis by chromosome analysis of fetal cells afterwards.

The $t(11 ; 22)(q 23 ; q 11)$ is the only known recurrent, non-Robertsonian constitutional translocation in human being. In more than $99 \%$ of cases, one of the parents of a proband with Emanuel syndrome is a balance carrier of $\mathrm{t}(11 ; 22)$ and is phenotypically normal. They are often identified after the birth of offspring with an unbalanced form of the translocation, the supernumeraryder(22)t(11;22) syndrome.

This syndrome is easily identified by routine G-band analysis. In the rare instance in which one of the parents is not a balanced translocation carrier, FISH probes for the 22q11.2 deletion and for the telomere of 11q can identify the supernumerary chromosome
B

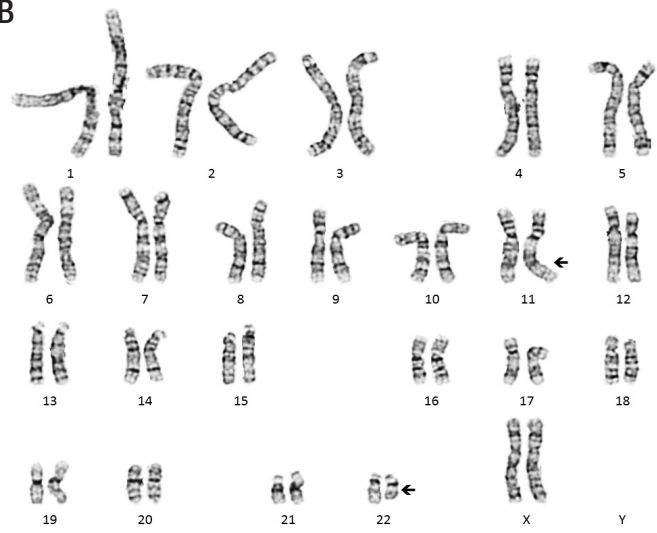

Fig. 1. A) The patient's karyotyping shows a supernumerary chromosome, der(22)t(11;22)(q23.3;q11.2). B) Her mother's karyotyping shows a balanced non-Robertsonian $\mathrm{t}(11 ; 22)$.

Table 1. Karyotypes and characteristics of patients with Korean cases

\begin{tabular}{lcccc}
\hline No. of cases & Karyotypes & Chromosome loci & Inheritance & \multicolumn{1}{c}{ Chracteristics } \\
\hline $1^{8)}$ & $47, X X,+\operatorname{der}(22) t(11 ; 22)$ & $q 25 ; q 13.1$ & Paternal & $\begin{array}{l}\text { IUGR, Cleft palate, low set ears, micrognathia, webbed neck, ASD, VSD, } \\
\text { pulmonary stenosis, Death }\end{array}$ \\
$2^{7)}$ & $47, X X,+\operatorname{der}(22) t(11 ; 22)$ & $q 23 ; q 11.2$ & Paternal & $\begin{array}{l}\text { Oligohydramnios, IUGR, low set ears, preauricular pit, micrognathia, high- } \\
\text { arched palate, winged scapula, ASD, both SNHL, developmental delay, } \\
\text { hypotonia }\end{array}$ \\
3 & $47, \mathrm{XX},+\operatorname{der}(22) t(11 ; 22)$ & $q 23.3 ; q 11.2$ & Maternal & $\begin{array}{l}\text { Cleft palate, low set ears, micrognathia, webbed neck, ASD, both SNHL, } \\
\text { vesicoureteral reflux, developmental delay, hypotonia, seizure }\end{array}$ \\
\hline
\end{tabular}

ASD, atrial septal defect; IUGR, intrauterine growth retardation; SNHL, sensorineural hearing loss; VSD, ventricular septal defect. 
in the karyotype as being derived from chromosomes 11 and 22. The clinical features of Emanuel syndrome arises from duplication of 22q10-22q11 and duplication of 11q23-qter on the supernumerary der(22). Most cases result from 3:1 meiotic segregation of the balanced translocation $\mathrm{t}(11 ; 22)(q 23 ; q 11)$. There is a single case report of supernumerary der(22) arising from translocation in the paternal germline with probable unbalanced adjacent 1 segregation and maternal non-disjunction of chromosome 22 in meiosis . . $^{9}$ Each sib of a proband with a carrier parent will either have supernumerary der(22) syndrome, be a balanced $\mathrm{t}(11 ; 22)$ carrier, or be spontaneously aborted as a result of supernumerary der(22) or another meiotic malsegregant.

This syndrome is characterized by multiple anomalies, but mortality is associated with life-threatening congenital malformations such as congenital heart defects, diaphragmatic hernia, or renal insufficiency. Depending on the age and extent of systemic involvement of the subject with Emanuel syndrome, they need to be cared by multiple displinary approaches with developmental assessment on a regular basis. Their siblings of patients need to determine the genetic risk for the offspring with Emanuel syndrome before pregnancy. If the siblings a balanced $t(11 ; 22)$ carrier, it is appropriate to offer genetic counseling that includes discussion of potential risks to offspring and productive option.

In summery, Emanuel syndrome is an inherited chromosome abnormality, characterized by multiple anomalies and developmental delay. In most of cases, a carrier parent has inherited the $t(11 ; 22)$ from one of his or her parents. Therefore parents of a proband with Emanuel syndrome should be offered chromosome analysis.

\section{References}

1) Carter MT, St Pierre SA, Zackai EH, Emanuel BS, Boycott KM. Phenotypic delineation of Emanuel syndrome (supernumerary derivative 22 syndrome): Clinical features of 63 individuals. Am J Med Genet A 2009;149A:1712-21.

2) Fraccaro $M$, Lindsten J, Ford $C E$, Iselius $L$. The 11q;22q translocation: a European collaborative analysis of 43 cases. Hum Genet 1980;56:21-51.

3) Iselius $L$, Lindsten J, Aurias $A$, Fraccaro $M$, Bastard $C$, Bottelli AM, et al. The 11q;22q translocation: a collaborative study of 20 new casesand analysis of 110 families. Hum Genet 1983;64:343-55.

4) Lin AE, Bernar J, Chin AJ, Sparkes RS, Emanuel BS, Zackai EH. Congenital heart disease in supernumerary der(22), $\mathrm{t}(11 ; 22)$ syndrome. Clin Genet. 1986;29:269-75.

5) Shaikh TH, Budarf ML, Celle L, Zackai EH, Emanuel BS. Clustered 11q23 and $22 q 11$ breakpoints and 3:1meiotic malsegregation in multiple unrelated t(11;22) families. Am J Hum Genet 1999;65:1595-607.

6) Edelmann L, Spiteri E, McCain N, Goldberg R, Pandita RK, Duong S, et al. A common breakpoint on 11q23 in carriersof the constitutional $\mathrm{t}(11$; 22) translocation. Am J Hum Genet 1999;65:1608-16.

7) Jun YS, So CH, Yu ST, Park DS, Cho EH, Oh YK. A case of supernumerary derivative(22) syndrome resulting from a paternal balanced translocation. J Korean Soc Neonatol 2010;17:127-31.

8) Lee $\mathrm{SH}$, Cho HC, Shin SK, Lee Jl, Choi WJ, Lee SA, et al. A case of partialtrisomy 22 due to paternal 11;22 translocation, t(11;22)(q25;q13.1). Korean J Obstet Gynecol 2002;45:1601-5.

9) Dawson AJ, Mears AJ, Chudley AE, Bech-Hansen T, McDermid H. $\operatorname{Der}(22) t(11 ; 22)$ resulting from a parental de novo translocation, adjacent 1 segregation and maternal heterodisomy of chromosome 22. J Med Genet 1996;33:952-6. 